\title{
Cáncer de pulmón y síndromes paraneoplásicos
}

\author{
B. JURADO GÁMEZ, Mª.D. GARCÍA DE LUCAS*, Mª . GUDÍN RODRÍGUEZ** \\ Unidad de Neumología, *Servicio de Medicina Interna. Área Sanitaria Norte. Córdoba \\ **Servicio de Neurología. Hospital Virgen de Alarcos. Ciudad Real.
}

\author{
LUNG CANCER AND PARANEOPLASTIC SYNDROMES
}

\section{RESUMEN}

En aquellos pacientes con una neoplasia, es relativamente común la aparición de un síndrome paraneoplásico (SP) que, en algunos de los casos, puede ser la manifestación clínica inicial. Entre los tumores malignos, se observa con mayor frecuencia en el cáncer de pulmón; este hecho es importante tenerlo en cuenta, sobre todo ante la presencia de un SP neurológico o endocrino que puede facilitar un diagnóstico más precoz y, en determinados casos, un tratamiento más eficaz de la enfermedad de base. La evolución del SP suele ser paralela a la del tumor subyacente, sin embargo, su manejo requiere, no sólo el control de la neoplasia, sino, además adoptar medidas terapéuticas específicas, ya que la evolución del $\mathrm{SP}$, como ocurre en la hipercalcemia maligna, puede amenazar la vida del paciente.

Se revisan los SP neurológicos y endocrinos más importantes asociados con el cáncer de pulmón.

PALABRAS CLAVE: Cáncer de pulmón. Síndrome paraneoplásico. Síndrome de Eaton-Lambert. Neuropatía sensorial subaguda. Encefalitis límbica. Secreción inadecuada de ADH. Síndrome de Cushing. Hipercalcemia maligna.

\begin{abstract}
Paraneoplastic syndromes (PNS) are a relatively common manifes tation of cancer, and in some cases they may be the first symptom. Lung cancer has the highest incidence of paraneoplastic syndrome. This fact is important considering a non explained endocrinological and neurologi cal syndrome, it may facilitate a prompt diagnosis, and in some cases an adequate treatment. PNS evolution seems to be parallel to the subjacent cancer. PNS management requires specific measures, because in some cases, it may compromise the patient life.

Neurological and endocrinological PNS associated to lung cancer are revised, and diagnosis and treatment of them are updated.
\end{abstract}

KEY WORDS: Lung cancer. Paraneoplastic syndromes. Eaton Lambert syndrome. Sensory subacute neuropathy. Lymbic encephalitis. Cushing syndrome. Malignancy associated hypercalcemia.

Jurado Gámez B, García de Lucas $M^{a} D$, Gudín Rodríguez $M^{a}$. Cáncer de pulmón y síndromes paraneoplásicos. An Med Interna (Madrid) 2001; 18: 440-446.

\section{INTRODUCCIÓN}

La incidencia global del carcinoma $(\mathrm{Ca})$ de pulmón sigue en aumento. En España en 1992 los tumores malignos fueron la causa más frecuente de muerte y la neoplasia pulmonar la más común entre los hombres (1).

La mayoría de los síntomas y signos de un cáncer se deben al crecimiento del tumor o a la infiltración local del mismo; en ocasiones, son las metástasis el origen de los síntomas en órganos lejanos a la localización primaria de la neoplasia. Sin embargo, los tumores pueden producir manifestaciones clíni- cas no relacionadas con la invasión por contigüidad, presencia de metástasis o efectos secundarios del tratamiento, manifestaciones que se engloban dentro del llamado síndrome paraneoplásico (2) (SP), término acuñado por Bouden en 1962.

El reconocimiento del SP en el Ca de pulmón es de gran interés, ya que, en determinadas ocasiones, es la primera manifestación de la neoplasia, lo cual permite un estudio y diagnóstico más precoz; también puede ser útil en la evolución, respuesta al tratamiento y posible recidiva del tumor. Por último, hay que tener en cuenta que, si el SP no se diagnostica y controla, puede ser una amenaza para la vida del

Trabajo aceptado: 19 de Octubre de 2000

Correspondencia: B. Jurado Gámez. Avda. Villanueva de Córdoba 36-1 14400 Pozoblanco (Córdoba). 
enfermo. Entre un 7-15\% de las neoplasias se manifiestan en algún momento de su evolución por alguna forma de SP (3), y el porcentaje en el Ca de pulmón alcanza al 10\% de los pacientes e involucra a muchos órganos y sistemas (4,5). En la tabla I se exponen los más frecuentes (2).

Se revisan los cuadros neurológicos más significativos como el síndrome de Eaton-Lambert, la encefalitis límbica y la neuropatía sensorial subaguda. También aquellos de origen endocrino como el síndrome de secreción inadecuada de ADH (SIADH), la secreción ectópica de ACTH y la hipercalcemia maligna. Se recuerda de forma somera los avances en la fisiopatología de estas entidades y se hace hincapié en las manifestaciones clínicas y manejo habitual.

\section{SÍNDROMES PARANEOPLÁSICOS NEUROLÓGICOS}

El Ca de pulmón se acompaña en un $10-15 \%$ de los casos de alguna complicación neurológica, generalmente de origen metastásico. El SP se presenta en aproximadamente el $1 \%$ de los pacientes con un tumor maligno, es más frecuente en el Ca broncogénico y el microcítico la estirpe histológica usualmente asociada a estas alteraciones paraneoplásicas (6-8), como son el S. miasteniforme de Eaton-Lambert (SMEL), la encefalitis límbica y la neuropatía sensorial subaguda (NSS), ello ocurre aproximadamente en el $3 \%$ de los pacientes.

\section{SÍNDROME MIASTENIFORME DE EATON-LAMBERT (SMEL)}

El SMEL es un trastorno autoinmune de la unión neuromuscular. Los pacientes con este síndrome tienen un $60 \%$ de posibilidades de presentar un Ca microcítico (9), esta posibilidad disminuye ostensiblemente después de dos años de evolución y es muy bajo a los cuatro años (10). El mecanismo por el cual el tumor participa en el desarrollo del SMEL, parece consistir en la formación de autoanticuerpos séricos IgG que interfieren con el funcionamiento de varios de los componentes extra e intracelulares de los canales del calcio presinápticos dependientes de voltaje de la unión neuromuscular $(11,12)$. El papel de los autoanticuerpos de los canales del calcio en la patogénesis del SMEL se ha confirmado al encontrarse, en las terminaciones nerviosas motoras del ratón, los hallazgos morfológicos y electrofisiológicos del SMEL después de inyectarle anticuerpos IgG de sujetos enfermos $(13,14)$. Mediante ensayos de inmunoprecipitación se ha encontrado que los anticuerpos reaccionan con canales del calcio de tipo $\mathrm{L}^{-15}, \mathrm{~N}-{ }^{15}$ y $\mathrm{P} / \mathrm{Q}-{ }^{16}$. Los autoanticuerpos séricos contra los canales del calcio del tipo P/Q- se encuentran en un 95\% de los pacientes con SMEL (12) y tienen una gran importancia en su patogénesis porque son los responsables de la liberación del neurotransmisor (acetilcolina) a la unión neuromuscular, su reducción explica la debilidad muscular y fatiga que caracteriza el síndrome (17).

Presentación clínica y diagnóstico. El SMEL puede preceder a la neoplasia en años. La presentación suele ser gradual e insidiosa, afecta más a los varones y se inicia hacia la mitad de la vida; el síntoma principal es la debilidad muscular que afecta predominantemente a los músculos proximales, sobre todo de la cintura pélvica y de las extremidades inferiores. Las mialgias y fatigabilidad son frecuentes, así como, los síntomas de disfunción autonómica como xerostomia, ortostatismo, impotencia y disminución de la sudoración (17). Los músculos oculomotores y orofaríngeos pueden afectarse con intensidad leve. La ptosis palpebral y la diplopia están presentes en un $25 \%$ de pacientes (9), y la debilidad de los músculos respiratorios raramente origina fallo respiratorio18. Los reflejos tendinosos profundos se encuentran disminuidos o ausentes, pero pueden potenciarse con la contracción mantenida del músculo, unos diez segundos, y esta respuesta es virtualmente diagnóstica del SMEL (19).

Electrofisiológicamente el SMEL se caracteriza por una baja amplitud del potencial de acción muscular, a diferencia de lo que ocurre en la miastenia gravis que es normal o casi normal, sin afectar a la velocidad de conducción. Tras ejercicio o estimulación repetida, el potencial de acción muscular aumenta a medida que se repiten los estímulos, sin que esta respuesta de facilitación sea modificada por la medicación anticolinesterasa. La biopsia muscular es inespecífica, muestra una atrofia de las fibras musculares tipo II.

Se investiga en la actualidad la utilidad de la determinación de los autoanticuerpos de los canales del calcio dependientes del voltaje para diagnosticar el SMEL y quizás, de forma precoz, el Ca microcítico de pulmón en pacientes sin SMEL (20). Como estos anticuerpos pueden desaparecer en enfermos tratados con inmunosupresores, su determinación debe efectuarse antes de iniciar la terapia. Su título no se correlaciona con la severidad del SMEL, en casos individuales han descendido al mejorar la enfermedad (21).

En cuanto al tratamiento, el síndrome sigue el curso evolutivo del tumor subyacente (22). Los anticolinesterásicos como la piridostigmina, en general, no producen mejoría. La guanidina y aminopiridinas son fármacos que aumentan la liberación de acetilcolina desde la terminación motora y elevan la concentración de calcio intracelular, lo cual mejora la transmisión neuromuscular y, por lo tanto, la debilidad muscular (10). Si no se obtiene la respuesta deseada, la plasmaféresis o la administración de gammaglobulina intravenosa suelen producir alivio rápido, aunque transitorio, de la clínica (23); en un intento de mantener la mejoría sintomática se utilizan los inmunosupresores como prednisona, azatioprina y ciclosporina, solos o combinados (24). Con igual objetivo, otra posibilidad a nuestro alcance, es repetir la plasmaféresis asociada a inmunosupresión (20). Deben evitarse en estos enfermos aquellos fármacos que comprometan la transmisión neuromuscular, caso de algunos antibióticos, antiarrítmicos o bloqueantes neuromusculares.

\section{NEUROPATÍA}

En esta entidad se afecta básicamente el axón respetándose relativamente la mielina. La característica típica en el estudio histológico es la de una gangliorradiculitis (10).

La NSS paraneoplásica es infrecuente, se asocia con el Ca microcítico en el 77\% de los casos (25) y puede preceder al diagnóstico de Ca pulmonar en meses (26). En un adulto con polineuropatía periférica e historia de tabaquismo prolongado, la seropositividad de los autoanticuerpos nucleares anti-neuronales tipo 1 (ANNA-1) también denominados Anti-Hu es un marcador de Ca microcítico de pulmón (27). Estos anticuerpos pueden detectarse en pacientes con $\mathrm{Ca}$ microcítico sin síntomas neurológicos pero no en personas sanas. Los ANNA-1 están presentes tanto en el líquido cefalorraquídeo 
como en el suero de pacientes con neuropatía sensitiva paraneoplásica (28). También se detectan en otros SP neurológicos existentes en el Ca microcítico como la encefalopatía límbica (29).

Se trata de anticuerpos IgG que reconocen específicamente a proteínas de peso molecular entre 35 y $40 \mathrm{kDa}$ expresadas en las neuronas y en las células del Ca microcítico $(28,30)$ y que constituyen una familia de proteínas fijadoras de RNA. Estos autoanticuerpos pueden no ser perjudiciales, aunque la amplia distribución de sus antígenos en el sistema nervioso refleja la gran diversidad de síndromes paraneoplásicos descritos en los portadores de anticuerpos ANNA-1 (31).

Clínicamente la NSS se caracteriza por el desarrollo subagudo de alteraciones asimétricas sensoriales como dolor, parestesias y entumecimiento que afecta distalmente a las extremidades, se acompaña de una ataxia sensorial que suele ser incapacitante. Los reflejos tendinosos profundos están abolidos, mientras que la función motora está preservada. Se asocia a alteraciones autonómicas (estreñimiento, síndrome sicca, e hipotensión ortostática). Al inicio de la enfermedad el estudio neurofisiológico puede ser normal, pero posteriormente se produce una ausencia o disminución de los potenciales sensitivos y evocados somatosensoriales (32). El manejo de este síndrome incluye el tratamiento del Ca subyacente, aunque generalmente no suele mejorar el cuadro neurológico que progresa de forma rápida. Con escasos resultados se han utilizado los corticoides, plasmaféresis, ciclofosfamida y azatioprina.

\section{ENCEFALITIS LÍMBICA}

Otra complicación característica del cáncer de pulmón es la encefalitis límbica, que en un 70\% de los casos se asocia al carcinoma de pulmón, especialmente al de células pequeñas (33). Los síntomas neurológicos pueden preceder al diagnóstico del carcinoma de pulmón en dos o tres años. En ocasiones el diagnóstico es necrópsico. Se puede iniciar como un síndrome ansioso depresivo, pero el síntoma más característico es el deterioro progresivo de la memoria reciente. Otras posibles complicaciones son las crisis parciales, la agitación, la confusión y la hipersomnia. El LCR está alterado suele mostrar pleocitosis y elevación de proteínas. La mayoría de los pacientes con encefalitis límbica tienen anticuerpos anti HU circulantes o ANNA-1, que se unen al núcleo de neuronas en lugares del cerebro, la médula y las células ganglionares de la médula (34). Los enfermos con otros síndromes paraneoplásicos sin anticuerpos anti $\mathrm{Hu}$ tienen menos riesgos de desarrollar esta complicación (35).

Algunos casos parecen responder a la plasmaféresis y a la administración intravenosa de inmunoglobulinas.

\section{OTRAS MANIFESTACIONES PARANEOPLÁSICAS DE TIPO NEUROLÓGICO}

Son el opsoclonus-mioclonus, el síndrome del hombre rígido y la retinopatía paraneoplásica, y una forma de enfermedad de neurona motora paraneoplásica. El opsoclonus mioclonus, se asocia al neuroblastoma de los niños, pero también se han descrito casos asociados al carcinoma de células pequeñas de pulmón (36).

\section{SÍNDROMES PARANEOPLÁSICOS ENDOCRINOS}

Es conocida la capacidad de algunos tumores no endocrinos, de forma especial el $\mathrm{Ca}$ broncogénico, para producir y liberar pequeñas cantidades de hormonas o precursores hormonales dando lugar a un SP. Entre las neoplasias pulmonares, o de cualquier otro órgano, los SP son más frecuentes en el Ca microcítico. Se observan con un porcentaje del $12 \%$, aunque esta cifra es variable, en función del criterio o grado de estudio que se exija, desde meramente clínico a exclusivamente analítico (subclínico).

Los SP de naturaleza endocrina más comunes se expresan en la tabla I. A continuación se revisan los SP más importantes que se observan en el Ca de pulmón.

\section{SECRECIÓN INAPROPIADA DE ADH (SIADH)}

En 1957 Schwartz y col. (37) describen, por primera vez, la hiponatremia asociada con una neoplasia pulmonar y la relacionan con una secreción inapropiada de hormona antidiurética.

El síndrome de SIADH se debe a la secreción mantenida de $\mathrm{ADH}$, en ausencia de estímulos osmóticos, no osmóticos y de cualquier otra causa de hiponatremia. Se caracteriza por hiponatremia, hipoosmolaridad plasmática, excreción renal de sodio continuada, ausencia clínica de deplección de volumen e incapacidad para diluir al máximo la orina a pesar de la hiponatremia 38. Además de las neoplasias existen otras causas que pueden originar hiponatremia siendo, por lo tanto, un diagnóstico de exclusión 39. La estirpe histológica que más se asocia con el SIADH es el Ca microcítico (40), el porcentaje varía entre el $2-10 \%$, y es más frecuente en el Ca extenso que en el limitado (6). En algunos pacientes los niveles de ADH son normales, en estos casos la hiponatremia se atribuye a la producción del factor atrial natriurético (ANF) por parte del tumor (41) que inhibe la reabsorción de sodio en el túbulo proximal y la liberación de renina y aldosterona. Aunque el $50 \%$ de los pacientes con $\mathrm{Ca}$ microcítico, tienen niveles altos de $\mathrm{ADH}$, sólo aquellos con una ingesta excesiva de agua desarrollan hiponatremia (42).

Clínica y diagnóstico. La sintomatología depende de la gravedad y velocidad de instauración de la hiponatremia más que del valor absoluto sérico de sodio (43). Las náuseas y vómitos son frecuentes, así como, los síntomas de intoxicación acuosa (agitación, confusión, crisis convulsivas y coma). Los criterios analíticos para el diagnóstico son la hiponatremia $(\mathrm{Na}<135 \mathrm{mmol} / \mathrm{l})$, hipoosmolalidad plasmática $(<280$ $\mathrm{mOsm} / \mathrm{kg}$ ), orina con dilución inferior a la máxima $(>200$ $\mathrm{mOsm} / \mathrm{kg}$ ) y excreción alta de sodio en ausencia de tratamiento diurético, fármacos capaces de estimular la secreción de $\mathrm{ADH}$, cuadros edematosos, o pérdidas renales o extrarrenales con deshidratación que puedan explicarlo, igualmente se requiere función tiroidea y suprarrenal normales.

Tratamiento. La medida más importante en el SIADH es el control de la neoplasia subyacente 39, en el Ca microcítico la administración de quimioterapia mantiene en el $88 \%$ de los pacientes niveles séricos de $\mathrm{Na}$ en rango de la normalidad.

Un balance hídrico negativo mediante la restricción líquida, menos de $800 \mathrm{ml}$ al día, origina una elevación discreta en el Na sérico, esta medida, sin embargo puede no ser adecuada en aquellos enfermos tratados con citostáticos 44 . Si a pesar 


\section{TABLA I}

SÍNDRO M ES PARANEO PLÁSICOS M ÁS FRECUENTES EN EL CÁNCER DE PULM ÓN

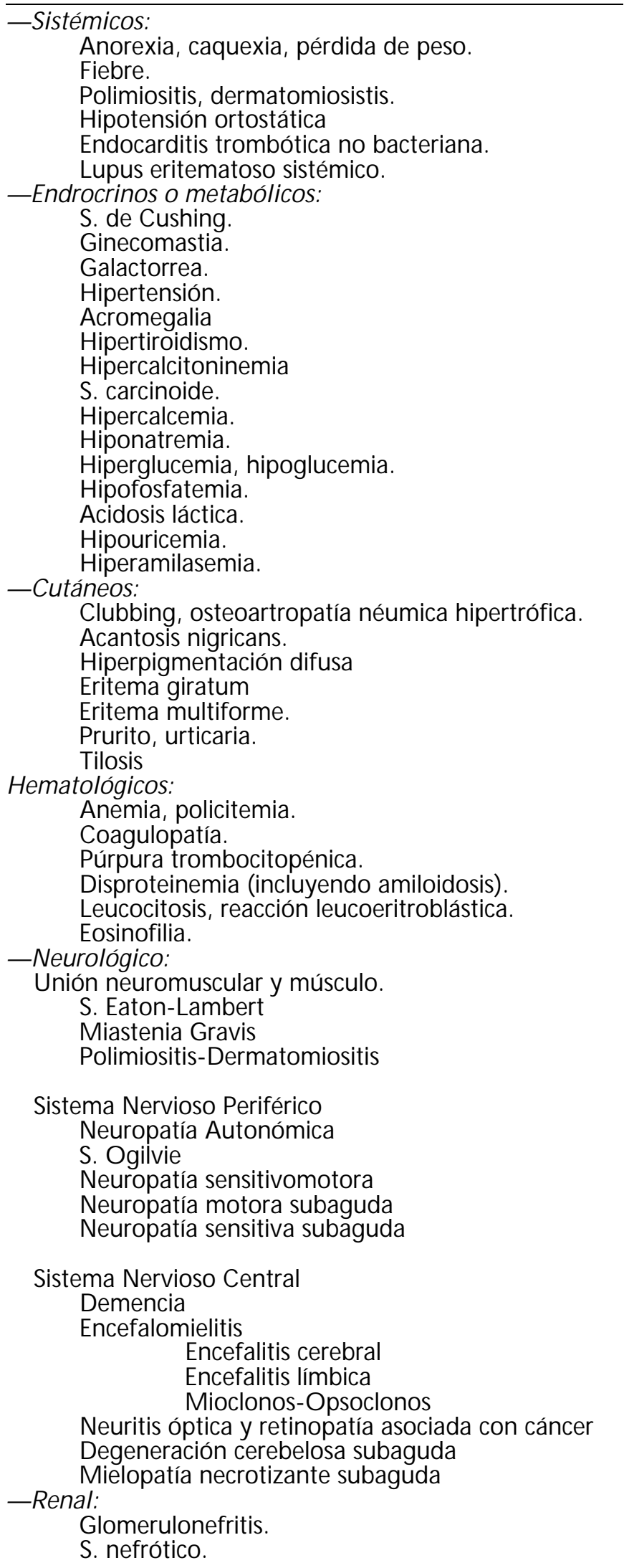

del recorte en el aporte de líquidos, persiste la hiponatremia se añadirá al tratamiento furosemida e incluso CINa vía oral.

El carbonato de litio es un medicamento que frecuentemente produce diabetes insípida nefrogénica como efecto secundario y por ello se ha utilizado como tratamiento del SIADH, sin embargo, es sólo efectivo en $20 \%$ de los pacientes y su administración prolongada se asocia con toxicidad renal, neurológica, cardíaca y tiroidea.

Otro fármaco que produce diabetes insípida nefrogénica es la demeclociclina, interfiere con la acción de la ADH y la dosis es de 0,9 a 1,2 g/día y alcanza su efecto máximo entre la primera y segunda semana de tratamiento. Los efectos secundarios más descritos son la retención de urea y la hipersensibilidad cutánea a los rayos ultravioleta.

La fluorcortisona, puede ser útil a dosis de 0,1 a $0,3 \mathrm{mg}$ dos veces al día, puede aumentar el Na sérico en 4 a 8 mmol/l.

La hiponatremia severa o asociada a síntomas neurológicos debe tratarse con suero salino hipertónico, añadir diuréticos del asa evitará una sobrecarga hídrica. El aumento del nivel sérico de $\mathrm{Na}$ debe ser lento, no superior a $25 \mathrm{mmol} / \mathrm{l}$ en las primeras 48 horas, ya que una reposición rápida puede asociarse, en un pequeño porcentaje de casos, a daño cerebral por lesión desmielinizante cerebral, síndrome de desmielinización osmótica, caracterizado por alteraciones motoras que incluyen tetraplejia, alteraciones del comportamiento, seudoparálisis de Bell, convulsiones y coma.

\section{PRODUCCIÓN ECTÓPICA DE ACTH}

La ACTH se produce en la hipófisis anterior, a partir del polipéptido pro-opiomelanocortina (POMC) y controla la liberación de cortisol en la corteza suprarrenal. La ACTH a su vez es regulada por la hormona liberadora de corticotropina (CRH). El RNAm del POMC tumoral (45) puede procesarse, entre otras moléculas, en ACTH activa que secretada a la circulación originará excesiva producción de gluco y mineralocorticoides por las suprarrenales.

Es el SP más frecuente, responsable del $15 \%$ de todos los casos de S. de Cushing y de la mayoría de los que ocurren en pacientes con cáncer, en casos muy aislados el S. de Cushing se origina por la producción ectópica de CRH (46). En el 72\% de los casos de $\mathrm{Ca}$ de pulmón, la concentración sérica de ACTH inmunorreactiva está elevada, aunque en parte es inactiva. Alrededor del 5\% de los enfermos con Ca microcítico desarrollan un síndrome de Cushing ectópico y acompaña a un $10 \%$ de los tumores carcinoides bronquiales (47).

Manifestaciones clínicas. El S. de Cushing ectópico asociado al Ca microcítico presenta generalmente una evolución inferior a 6 meses y se caracteriza por hipertensión, debilidad de músculos proximales e hiperglucemia. Existe alcalosis hipocaliémica por el exceso de mineralocorticoides, alteración que es rara en la enfermedad de Cushing (48). Sin embargo, en los tumores de crecimiento más lento se observará un cuadro clínico mucho más florido con obesidad centrípeta, estrías cutáneas, cuello de búfalo, hiperpigmentación e hirsutismo.

Diagnóstico. Cuando aparecen los síntomas del S. de Cushing, la existencia de lesiones radiológicas sugieren la presencia de un Ca broncogénico. En todos los casos está elevado el cortisol plasmático y urinario y se pierde el ritmo circadiano. En general, no hay disminución del cortisol urinario tras la 
supresión con dosis altas de dexametasona ( $8 \mathrm{mg} /$ día $)$ salvo en un tercio de los tumores carcinoides. En la mayor parte de los casos la ACTH presenta una elevación marcada, por encima de $200 \mathrm{pg} / \mathrm{ml}$. Si los tests citados no son concluyentes, se realizará una medición de los niveles de ACTH en las venas de los senos petrosos inferiores tras estímulo con CRF $(49,50)$.

Tratamiento. El control eficaz del Ca subyacente es el tratamiento óptimo del cuadro endocrino, en el caso del $\mathrm{Ca}$ microcítico será la quimioterapia, o la cirugía en el tumor carcinoide.

En el Cushing ectópico el hipercortisolismo se trata primariamente con inhibidores enzimáticos adrenales y antagonistas de los receptores de glucocorticoides como mifepristona y octreotida (51). La embolización arterial adrenal y adrenalectomía bilateral puede considerarse en los casos con una supervivencia estimada superior a dos años o ante la falta de respuesta al tratamiento médico (52).

La mejoría sintomática puede conseguirse mediante el tratamiento con inhibidores enzimáticos de la esteroidogénesis como el ketoconazol, metirapona y aminoglutetemida, sólos o en combinación. El ketoconazol (53), administrado sólo o en combinación con quimioterapia, a una dosis de 400-800 $\mathrm{mg}$ /día reduce en $2 / 3$ de los pacientes la excreción de cortisol urinario. Los antagonistas periféricos de los glucocorticoides, mifepristona, o el octreotida, pueden ser utilizados igualmente sólos o en combinación con los inhibidores adrenales.

\section{HIPERCALCEMIA ASOCIADA A MALIGNIDAD}

Es el SP más frecuente y alcanza en algunas series el $40 \%$ de todas las causas de hipercalcemia. Se detecta entre el 5$20 \%$ de los pacientes con cáncer y generalmente es una manifestación de enfermedad oncológica diseminada.

El mantenimiento de un nivel normal de calcio sérico, depende de la interrelación de tres sistemas hormonales, la vitamina $\mathrm{D}$, calcitonina y la hormona paratiroidea $(\mathrm{PTH})$, cada una de ellas es controlada, directa o indirectamente, por el calcio sérico ionizado mediante un mecanismo de retroalimentación (54).

Aproximadamente entre el 5 y el $38 \%$ de los enfermos con Ca broncogénico, en algún momento de su enfermedad, tienen hipercalcemia y el $\mathrm{Ca}$ de células escamosas es la estirpe histológica habitual con el $73 \%$ de todos los tumores, le sigue el Ca de células grandes y el adenocarcinoma, $10 \%$ de los casos cada uno, la hipercalcemia es rara como SP en el Ca microcítico (55).

Patogénesis. En 1941, es Albright quien postula, por vez primera, la hipótesis de la producción de PTH por un tumor como causa de la hipercalcemia asociada a una neoplasia. Los mecanismos más importantes involucrados en la hipercalcemia son la osteolisis local y la hipercalcemia humoral 56, el primero representa menos del $20 \%$ de los casos y se atribuye a factores elaborados localmente por las células tumorales que actúan reabsorbiendo hueso. Entre los factores osteoclásticos involucrados se incluyen el factor de necrosis tumoral (TNF), linfotoxina, prostaglandinas E2, interleukina- 6 e interleukina 1. El Ca microcítico, aún cuando presente afectación ósea, no suele producir hipercalcemia debido a que posee una estimulación osteoclástica menor.

La hipercalcemia humoral es el mecanismo más importante en el 56 al $80 \%$ de los pacientes afectados. Es consecuencia de la elaboración de factores que actúan a nivel sistémico con capacidad reabsortiva sobre el hueso y en menor grado, de reabsorción de calcio en el riñón. Entre los mediadores humorales implicados, el más importante es el péptido relacionado con la PTH (PTH-rP), otros son el factor de crecimiento transformante alfa, TNF y la interleuikina-1. La PTH-rP no es una auténtica hormona pero imita algunas acciones de la PTH, origina además de hipercalcemia, hipofosfatemia y elevación de la excreción de AMPc urinario (57). Los 13 primeros aminoácidos de la PTHrP y hormona paratiroidea son homólogos en el $70 \%$, un hecho que ayuda a explicar el parecido clínico entre hipercalcemia maligna humoral e hiperparatiroidismo primario. Las estructuras secundarias y terciarias de las dos hormonas de 14 a 36 aminoácidos son también similares, lo cual favorece la afinidad de la PTHrP por el receptor de la hormona paratiroidea. En general, el nivel de PTHrP se correlaciona con la calcemia (58).

Manifestaciones clínicas y diagnóstico. El calcio es un regulador de importantes funciones celulares. Los pacientes con niveles séricos elevados pueden presentar una gran variedad de síntomas derivados de la afectación de múltiples órganos (Tabla II). Las manifestaciones dependen fundamentalmente de la rapidez de instauración de la hipercalcemia, su nivel sérico no se correlaciona siempre con la gravedad de los síntomas (59), si bien, los enfermos con cifras superiores a 14 $\mathrm{mg} / \mathrm{dL}$ están siempre sintomáticos. La presentación clínica suele ser inespecífica, y es habitual la presencia de letargia, confusión, fatiga, náuseas, anorexia y somnolencia.

En relación con el diagnóstico, se excluirán otras causas de hipercalcemia. La elevación sérica de PTH medida por inmunoensayo sugiere hiperparatiroidismo primario. Un nivel normal de PTH y bajo de fósforo, en ausencia de metástasis

\section{TABLA ॥}

M ANIFESTACIO NES DE LA HIPERCALCEM IA (55)

\section{Sistema neurológico:}

Alteración del estado mental, confusión letargia, coma, cambio de personalidad, alucinaciones, sicosis, reflejos osteotendinosos disminuidos, fuerza muscular disminuida incluyendo a la musculatura respiratoria, alteraciones en electroencefalograma.

\section{Alteraciones cardíacas:}

Irritabilidad y contracción cardíaca aumentada, mayor sensibilidad a la digital, cambios electrocardiográficos, PR y QRS prolongado: acortamiento del intervalo QT; en hipercalcemia severa: aplanamiento de la onda $T$ y aumento del intervalo QT; bradiarritmia, bloqueo de rama, bloqueo completo, parada cardíaca

\section{Gastrointestinal:}

Anorexia, náuseas, vómitos, estreñimiento, dolor abdominal, distensión. Renal:

Renal:

Poliuria, polidipsia, deshidratación.

Sistema esquelético: Dolor óseo, fracturas. 
óseas, hacen sospechar hipercalcemia humoral, mientras que un valor normal de ambos indicaría hipercalcemia local osteolítica. En la hipercalcemia humoral casi siempre se detectan niveles elevados de PTHrP.

Tratamiento. En el contexto de un Ca de pulmón, la hipercalcemia se correlaciona con una masa tumoral grande y una mala supervivencia tras su descubrimiento, media de 1 a 3 meses (60), teniendo en cuenta este mal pronóstico es necesario un manejo individualizado; de esta forma, si el paciente muestra una hipercalcemia grave y las posibilidades de controlar la neoplasia son altas, es importante realizar un tratamiento enérgico, por el contrario, si la neoplasia se encuentra en fase avanzada se requerirán medidas más conservadoras dado el efecto sedante que poseen los niveles elevados de calcio.

El manejo incluye una adecuada reposición de volumen y la administración de inhibidores de la reabsorción ósea $(61,62)$. La rehidratación es una medida terapéutica importante, el paciente suele estar deshidratado, ya que, el calcio antagoniza la acción de la hormona antidiurética en el riñón y produce poliuria. Además la hipercalcemia favorece la aparición de vómitos y somnolencia que dificulta la ingesta de líquidos y origina un balance hídrico negativo. El volumen se repone con suero salino, se aumenta con ello la tasa de filtrado glomerular y la carga de calcio filtrado y desciende la reabsorción de $\mathrm{Na}$ en el túbulo próximal. La perfusión salina será inicialmente de unos tres litros/día, con esta medida se reduce la calcemia de 1,5 a 2,5 mg/dL. En situaciones críticas la perfusión de suero isotónico puede elevarse a 6 L/día. Una vez rehidratado el paciente y siempre que se administre volúmenes altos, es necesaria la utilización de diuréticos del asa, tipo furosemida, que ayudan a inhibir el mecanismo de reabsorción tubular del calcio y evita la sobrecarga de volumen. El tratamiento debe acompañarse de la administración de bloqueantes de la reabsorción ósea.

La calcitonina, actúa rápidamente inhibiendo la reabsorción ósea y aumentando la excreción renal de calcio, aunque su acción es ligera y puede aparecer taquifilaxia a partir de las
24-72 horas de tratamiento. Su acción es rápida y segura en pacientes deshidratados y con insuficiencia renal (63). Una ventaja adicional es la mejoría del dolor en pacientes con afectación ósea. Puede ser útil mientras se logra el control con otros fármacos que se exponen a continuación.

Un inhibidor de la reabsorción ósea, la plicamicina (mitramicina), tiene un efecto tóxico en el osteoclasto e inhibe la reabsorción ósea, una dosis única puede normalizar la calcemia, si se requiere, se repetirá a las 24-48 horas, un inconveniente es la recomendación de emplear una vía venosa central, la dosis es de $25 \mathrm{Fg} / \mathrm{kg}$ y se perfunde en embolada lenta. Si es necesario, por recidiva de la hipercalcemia, se administrará dos veces por semana a dosis de $10 \mathrm{Fg} / \mathrm{kg}$. Sus efectos secundarios incluyen toxicidad hepática, trombopenia y trastornos de la coagulación. El uso de la plicamicina ha disminuido al ser desplazada por los bifosfonatos, fármacos menos tóxicos.

El nitrato de galio previene la reabsorción de hueso por inhibición de los osteoclastos y por adsorción y reducción de la solubilidad de los cristales de apatita, mejora la hipercalcemia en hasta el $86 \%$ de los pacientes tratados. La nefrotoxicidad es su mayor efecto secundario y su mayor inconveniente la duración de su perfusión (5 días).

Los bifosfonatos son análogos estructurales del pirofosfato que se unen a los cristales de hidroxiapatita e inhiben la reabsorción ósea osteoclástica y disminuyen la eliminación urinaria de calcio e hidroxiprolina. El clodronato y el pamidronato inhiben el reclutamiento y función de los osteoclastos sin afectar la mineralización del nuevo osteoide, al contrario que el etidronato. Una dosis única de 60 a $90 \mathrm{mg}$ de pamidronato normaliza la calcemia en el 80 a $100 \%$ de los pacientes manteniéndose su efecto durante semanas. En pacientes con hipercalcemia humoral, el tratamiento con bifosfonatos puede ser menos efectivo porque está aumentada la reabsorción tubular renal de calcio, en algunos casos es necesario repetir la dosis.

En la actualidad los bifosfonatos de segunda generación, pamidronato, son los agentes de elección en la hipercalcemia maligna por su eficacia y menor toxicidad, lo más frecuente es la aparición de febrícula en un $20 \%$ de los pacientes.

\section{Bibliografía}

1. Alonso I, Regidor E, Rodríguez C, Gutiérrez-Fisac JL. Principales causas de muerte en España, 1992. Med Clin (Barc) 1996; 107: 441-5.

2. Patel AM, Davila DG, Peters SG. Paraneoplastic syndromes associated with lung cancer. Mayo Clin Proc 1993; 68: 278-87.

3. Abeloff MD. Paraneoplastic syndromes. A window on the biology of cancer. N Engl J Med 1987; 317: 1589-600.

4. Andersen HA, Prakash UBS. Diagnosis of symptomatic lung cancer. Semin Respir Med 1982; 3: 165-75.

5. Grippi MA. Clinical aspects of lung cancer. Semin Roentgenol 1990; 25: 12-24.

6. Dearnaley D. Small-cell lung cancer. Lancet, 1995; 345: 1285-9.

7. Elrington GM, Murray NMF, Spiro SG, et al. Neurological paraneoplastic syndrome in patients with small cell lung cancer. A prospective survey of 150 patients. J Neurol Neurosurg Psych 1991; 54: 764-7.

8. Vázquez Almuiña J, Bermúdez JR, Mosquera F, Del Río V, Touza C, Muñoz F. Mielopatía paraneoplásica, probablemente mielopatía necrotizante: a propósito de un caso asociado a carcinoma anaplásico de células pequeñas. An Med Interna (Madrid) 1995; 12: 445-446.

9. O'Neill JH, Murray NMF, Newsom-Davis J. The Lambert-Eaton myasthenic syndrome. A review of 50 cases. Brain 1988; 111: 577-96.

10. Stübgen JP. Neuromuscular disorders in systemic malignancy and its treatment. Muscle Nerve 1995; 18: 636-48.

11. Motomura M, Johnston I, Lang B, Vincent A, Newsom-Davis J. An improved diagnostic assay for Lambert-Eaton myasthenic syndrome. J Neurol Neurosurg Psychiatry 1995; 58: 85-7.

12. Lennon VA, Kryzer TJ, Griesman GE, et al. Calcium-channel antibodies in the Lambert-Eaton syndrome and other paraneoplastic syndromes. N Engl J Med 1995; 332: 1467-74.

13. Lang B, Newsom-Davis J, Wray D, Vincent A. Autoinmune aetiology for myasthenic (Eaton-Lambert) syndrome. Lancet 1981; 2: 224-6.

14. Fukunaga H, Engel AG, Lang B, Newson-Davis J, Vincent A. Passive transfer of Lambert-Eaton myasthenic syndrome with IgG from man to mouse depletes the presynaptic membrane active zones. Proc Natl Acad Sci USA 1983; 80: 7636-40.

15. El Far O, Marqueze B, Leveque C, et al. Antigens associated with Nand L-type calcium channels in Lambert-eaton myasthenic syndrome. $\mathrm{J}$ Neurochem1995; 64: 1696-702.

16. Motomura M, Lang B, Johnston I, Palace J, Vincent A, Newson-Davis J. Incidence of serum anti-P/Q-type and antiN-type calcium channel autoantibodies in the Lambert-Eaton myasthenic syndrome. J Neurol Sci 1997; 147: 35-42.

17. O'Suilleabhain P, Low PA, Lennon VA. Autonomic dysfunction in the 
Lambert-Eaton myasthenic syndrome. Neurology 1998; 50: 88-93.

18. Beydoun SR. Delayed diagnosis of Lambert-Eaton myasthenic syndrome in a patient presenting with recurrent refractory respiratory failure. Muscle Nerve 1994; 17: 689-90

19. Nilsson O, Rosen I. The stretch reflex in the Eaton-Lambert syndrome, myasthenia gravis and myotonic dystrophy. Acta Neurol Scand 1978; 57: $350-7$

20. Sanders DB. Lambert-Eaton myasthenic syndrome: clinical diagnosis, inmune-mediated mechanisms and update on therapies. Ann Neurol 1995; 37 (S1): S63-S73.

21. Leys K, Lang B, Vincent A, Newson-Davis J. Calcium channel autoantibodies in the Lambert-Eaton syndrome. Ann Neurol 1991; 29: 307-14.

22. Chalk CH, Murray NM, Newsom-Davis J, et al. Response of the Lambert-Eaton myasthenic syndrome to treatment of associated small-cell lung carcinoma. Neurology 1990; 34: 1324-30.

23. Bird SJ. Clinical and electrophysiologic improvement in the LambertEaton syndrome with intravenous immunoglobulin therapy. Neurology 1992; 42: 1422.

24. Lundh H, Nilsson O, Rosen I. Current therapy of the Lambert-Eaton myasthenic syndrome. Prog Brain Res 1990; 84: 163-70.

25. Dalmau J, Graus F, Rosenblum MK, et al. Anti-Hu-associated paraneoplastic encephalomyelitis-sensory neuronopathy. Medicine 1992; 71: 59-72.

26. Kimmel DW, O`Neill BP, Lennon VA. Subacute sensory neuronopathy associated with small cell lung carcinoma: diagnosed aided by autoimmune serology. Mayo Clin Proc 1988; 63: 29-32.

27. Lennon VA. Paraneoplastic autoantibodies: the case for a descriptive generic nomenclature. Neurology 1994; 44: 2412-5.

28. Graus F, Elkon KB, Cordon-Cardo C, Posner JB. Sensory neuronopathy and small cell lung cancer: antineuronal antibody that also reacts with the tumor. Am J Med 1986; 80: 45-52.

29. Dropcho EJ. Autoinmune central nervous system paraneoplastic disorders: mechanisms, diagnosis, and therapeutic options. Ann Neurol 1995; 37(S1): S102-S113.

30. Dalmau J, Furneaux HM, Gralla Rj, Kris MG, Posner JB. Detection of the anti-Hu antibody in the serum of patients with small cell lung cancer: a quantitative Western blot analysis. Ann Neurol 1990; 27: 544-52.

31. Lucchinetti CF, Kimmel DW, Lennon VA. Paraneoplastic and oncologic profiles of patients seropositive for type 1 antineuronal nuclear autoantibodies. Neurology 1998; 50: 652-7.

32. Horwich MS, Cho 1, Porro S, Posner JB. Subacute sensory neuropathy: a remote effect of carcinoma. Ann Neurol 1977; 2: 7-19.

33. Corsellis JAN, Goldberg GJ, Norton AR. Limbic encephalitis and its association with lung carcinoma. Brain 1968; 91: 487.

34. Lamowitch S, Graus F, Uchuya M, Rene R, Bescansa E, Delattre JY. Limbic encephalitis and small cell lung cancer. Clinical and immunological features. Brain 1997; 120: 923-8.

35. Verschuuren JJ, Perquin M, ten Velde G, De Baets M, Vriesman PB, Twijnstra A. Anti-Hu antibody titre and brain metastases before and after treatment for small cell lung cancer. J Neurol Neurosurg Psychiatry 1999; 67: 353-7.

36. Posner JB, Dalmau J. Paraneoplastic syndromes. Curr Opin Immunol 1997; 9: 723-9.

37. Schwartz WD, Bennett W, Curelop S, Bartter F. A syndrome of renal sodium loss and hyponatremia probably resulting from inappropriate secretion of antidiuretic hormone. Am J Med 1957; 23: 529-42.

38. Sorensen JB; Andersen MK, Hansen HH. Syndrome of inappropriate secretion of antidiuretic hormone (SIADH) in malignant disease. J Intern Med 1995; 238: 97-110.

39. List AF, Hainsworth JO, Davis BW, et al. The syndrome of inappropriate secretion of antidiuretic hormone (SIADH) in small cell lung cancer. J Clin Oncol 1986; 4: 1191-8.
40. Oosterhout AG, van de Pol M, ten Velde gp, Twijnstra A. Neurolgic disorders in 203 consecutive patients with small cell lung cancer. Results of longitudinal study. Cancer 1996; 77: 1434-41.

41. Gross AJ, Steinberg SM, Reilly JA, et al. Atrial natriuretic factor and arginine vasopressin production in tumor cell lines from patients with lung cancer and their relationship to serum sodium. Can Res 1993; 53 : 67-74.

42. Moses AM, Scheinman SJ. Ectopic secretion of neurohypophyseal peptides in patients with malignancy. Endocrinol Metab Clin North Am 1991; 20: 489-506.

43. Decaux G, Waterlot Y, Genette F, Mockel J. Treatment of the syndrome of inappropriate secretion of antidiuretic hormone with furosemide. $\mathrm{N}$ Engl J Med 1981; 304: 329-30.

44. Kovacs L, Robertson GL. Syndromes of inappropriate antidiuresis Endo Metab Clin North Am. 1992; 21: 859-75.

45. Schteingart DE. Ectopic secretion of peptides of the proopiomelanocortin family. Endo Metab Clin North Am 1991; 20: 453-71.

46. Delisle L, Boyer MJ, Warr D, Killinger D, Payne D, Yeoh JL, Feld R. Ectopic corticotropin syndrome and small- cell carcinoma of the lung. Arch Intern Med 1993; 153: 746-52.

47. Jex RK, van Heerden JA, Carpenter PC, Grant Cs. Ectopic ACTH syndrome: diagnostic and therapeutic aspectcs. Am J Surg 1985; 149: 276-82.

48. Shepherd FA, Laskey J, Evans WK et al. Cushing's syndrome associated with ectopic corticotropin production and small cell lung cancer. $\mathrm{J}$ Clin Oncol 1992; 10: 21-7.

49. Kaye TB, Crapo L. The Cushing Syndrome: an update on diagnostic tests. Ann Intern Med 1990; 112: 434-4.

50. Freda PU, Wardlaw SL, Bruce JN, Post KD, Goland RS. Differential diagnosis in Cushing Syndrome. Medicine 1995; 74: 74-82.

51. Ortho DN. Cushing's syndrome. N Engl J Med 1995; 332: 791-803.

52. Schteinggart DE. Cushing's Syndrome. Endocrinol Metab Clin North Am 1989; 18: 311-38.

53. Winquist EW, Laskey J, Crump M, Khamsi F, Sheperd FA. Ketoconazole in the management of paraneoplastic Cushing's syndrome secondary to ectopic adrenocorticotropin production. J Clin Oncol 1995; 13 . 157-64.

54. Yates AJP, Gutierrez GE, Smolens P, Travis PS, Katz MS, Aufdemorte TB, et al. Effects of a synthetic peptide of a parathyroid hormone-related protein on calcium homeostasis, renal tubular calcium reabsorption, and bone metabolism in vivo and in vitro in rodents. J Clin Invest 1988; 81: $932-8$

55. Arroliga AC, Matthay RA. Paraneoplastic syndromes in bronchogenic carcinoma. Clin Pulm Med 1994; 1: 322-32.

56. Gaich G, Burtis WJ. The diagnosis and treatment of malignancy associated hypercalcemia . Endocrinologist 1991; 1: 371-9.

57. Bajorunas RD. Clinical manifestations of cancer related hypercalcemia. Semin Oncol 1990: 17: 16-25.

58. Budayr AA, Nissenson RA, Klein RF et al. Increased serum levels of a parathyroid hormone-like protein in malignancy-associated hypercalcemia. Ann Inter Med 1989; 111: 807-12.

59. Burtis JW, Brady TG, Orloff JJ, et al. Inmunochemical characterization of circulating parathyroid hormone related protein in patients with humoral hypercalcemia of cancer. N Eng J Med 1990; 322: 1106-12.

60. Vassilopoulo-Sellin R, Newman BM, Taylor SH, Guinee VF. Incidence of hypercalcemia in patients with malignancy referred to a comprehensive cancer center. Cancer 1993; 71: 1309-12.

61. Bilezikian JP. Management of acute hypercalcemia. N Engl J Med 1992; 326: 1196-203.

62. Gonzalez Barón M, De la Gándara Porres I, Zamora P. Hipercalcemia tumoral. Med Clin 1992; 98: 631-4.

63. Wisneski AL. Salmon calcitonin in acute management of hypercalcemia. Calcif Tissue Int 1990; 46: 26-30. 